\title{
Improvement in glucose tolerance due to Momordica charantia (karela)
}

\author{
B A LEATHERDALE, R K PANESAR, G SINGH, T W ATKINS, C J BAILEY, A H C BIGNELL
}

\begin{abstract}
The effect of karela (Momordica charantia), a fruit indigenous to South America and Asia, on glucose and insulin concentrations was studied in nine non-insulindependent diabetics and six non-diabetic laboratory rats. A water-soluble extract of the fruits significantly reduced blood glucose concentrations during a $50 \mathrm{~g}$ oral glucose tolerance test in the diabetics and after force-feeding in the rats. Fried karela fruits consumed as a daily supplement to the diet produced a small but significant improvement in glucose tolerance. Improvement in glucose tolerance was not associated with an increase in serum insulin responses.
\end{abstract}

These results show that karela improves glucose tolerance in diabetes. Doctors supervising Asian diabetics should be aware of the fruit's hypoglycaemic properties.

\section{Introduction}

Karela (Momordica charantia), known also as cundeamor or bitter gourd, is a vegetable indigenous to South America and Asia that has been used there to treat diabetes, leprosy, jaundice, rheumatism, and gout. ${ }^{1}$ We report improved glucose tolerance in non-insulin-dependent diabetics and laboratory rats taking karela.

\section{Patients, methods, and results}

We studied nine Asian diabetic outpatients (six men and three women). Their mean weight was $68.4 \mathrm{~kg}$ before and $68.0 \mathrm{~kg}$ at the end of the study, and all were $92-110 \%$ of their ideal weight.

\footnotetext{
Department of Diabetes and Endocrinology, Clinical Investigation Unit, and Department of Biological Sciences, Dudley Road Hospital and University of Aston, Birmingham

B A LEATHERDALE, BSC, MRCP, consultant physician

R K PANESAR, BSC, MPS, pharmacist

G SINGH, BSC, research assistant

$T$ W ATKINS, BSC, PHD, lecturer in biochemistry

C J BAILEY, BSC, PHD, lecturer in physiology

A $\mathrm{H}$ C BIGNELL, MSC, $M C B$, top-grade biochemist
}

Treatment was diet alone (one patient) or diet and chlorpropamide (three patients), tolbutamide (three), glibenclamide (one), or glymidine (one).

Patients underwent three $50 \mathrm{~g}$ oral glucose tolerance tests: a standard test, a test with $50 \mathrm{ml}$ karela juice, and a test after eight to 11 weeks of taking fried karela $(0.23 \mathrm{~kg})$ daily. Patients omitted drugs for 48 hours, fasted, and did not smoke from 2200 on the day before each test. The test with added karela juice was performed before the standard test in two cases. The test with added karela juice and the standard test were performed at an interval of seven to 10 days, and glucose and insulin concentrations were estimated on venous blood sampled every half hour for two hours. Fasting glycosylated haemoglobin was also measured.

Juice was extracted from $0.9 \mathrm{~kg}$ fresh karela obtained locally. This usually yielded $200-250 \mathrm{ml}$, which was obtained by crushing the outer shells with a pestle and mortar, after removal of the seeds, and collecting the juice through muslin to remove debris. Patients were instructed how to fry slices of karela in vegetable oil in a standard fashion.

Juice obtained as described was concentrated by rotary evaporation at $40^{\circ} \mathrm{C}$. Non-diabetic Sprague-Dawley rats (average weight $200 \mathrm{~g}$ ) were given either $2.0 \mathrm{ml}$ of a tenfold concentrate or $2.0 \mathrm{ml}$ of physiological saline by stomach tube. Concentration of the juice was expressed in relation to wet weight-that is, $10 \mathrm{ml}$ obtained from $100 \mathrm{~g}$ karela gives a tenfold concentration. Insulin and glucose concentrations were estimated on blood sampled half hourly from the rats' tails. Glucose concentrations were estimated using a YSI Analyser Model 23AM (Clandon Instruments) in diabetics and a Beckman Analyser (Beckman Riic Ltd) in rats. Insulin concentration was measured by radioimmunoassay with reagents supplied by the Radiochemical Centre, Amersham, using either human insulin (Wellcome Reagents Ltd, Beckenham) or rat insulin (Novo Industria A/S, Copenhagen) standards. Glycosylated haemoglobin was measured by a modification of the method of Welch and Boucher. ${ }^{2}$ Results were compared using paired $t$ tests (diabetics) or unpaired $t$ tests (rats).

Karela juice reduced both the plasma glucose concentration (figure) and the area under the mean incremental glucose curves. The areas under the curves were $1.2 \pm 0.9 \mathrm{mmol} \mathrm{min} / 1(\mathrm{p}<0.05)$ at 0 -30 minutes, $4 \cdot 0+1 \cdot 7(\mathrm{p}<0 \cdot 01)$ at $30-60$ minutes, and $5 \cdot 8+3 \cdot 4$ $(\mathrm{p}<0.001)$ at $60-90$ minutes during the test with karela juice added; and $1.5 \pm 0.6(\mathrm{p}<0.01), 4.4 \pm 1.1(\mathrm{p}<0.05)$, and $5.6 \pm 1.8 \mathrm{mmol} \mathrm{min} / 1$ $(\mathrm{p}<0.05)$ respectively during the test after patients had taken fried karela compared with $2 \cdot 0 \pm 0 \cdot 7,5 \cdot 6 \pm 2 \cdot 0$, and $7 \cdot 0 \pm 2 \cdot 6 \mathrm{mmol} \mathrm{min} / 1$ respectively after the standard test.

In rats given physiological saline the blood glucose concentration did not change, but in those given karela it had fallen at 30 minutes to $4 \cdot 7 \pm 0.4 \mathrm{mmol} / 1(85 \pm 7 \mathrm{mg} / 100 \mathrm{ml})$ from $7 \cdot 9 \pm 0.3 \mathrm{mmol} / \mathrm{l}(142 \pm$ $5 \mathrm{mg} / 100 \mathrm{ml}$ ) (a $41 \%$ reduction). This fall persisted for two hours. 


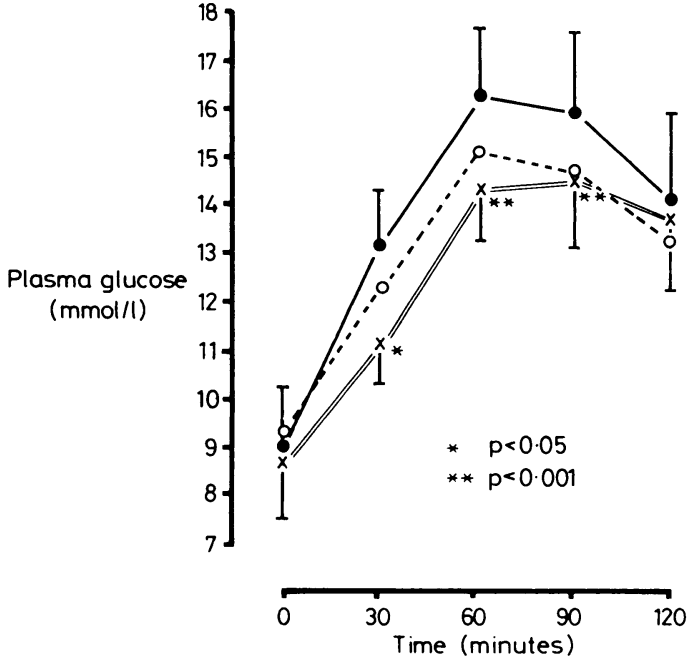

Mean plasma glucose concentration during standard oral $50 \mathrm{~g}$ glucose tolerance test ( - $)$, glucose tolerance test with karela juice $(x=\times)$, and glucose tolerance test after consumption of $0.23 \mathrm{~kg}$ fried karela daily $(\bigcirc---\bigcirc)$. Vertical bars represent standard error of mean and are not shown for the test using fried karela for the sake of clarity. ${ }^{*} \mathrm{p}<0.05 . \quad{ }^{* *} \mathrm{p}<0.01$.

Conversion: SI to traditional units-Glucose: $1 \mathrm{mmol} / 1 \approx 18 \mathrm{mg} / 100 \mathrm{ml}$

Insulin concentrations with karela in the diabetics and rats were significantly different from the results in the standard test only twice. The initial concentration in the test with karela juice added was significantly higher than that in the standard test $(31.3 \pm 13.7 v$ $24.6 \pm 10.6 \mathrm{mU} / 1 ; \mathrm{p}<0.05)$; and the concentration at 60 minutes in the test after the patients had taken fried karela was significantly lower than that in the standard test $(42.3 \pm 22.8 v 75.2 \pm 50.5 \mathrm{mU} / 1$; $\mathrm{p}<0.05)$.

Glycosylated haemoglobin was $17 \cdot 9+3.1 \%$ after patients had taken fried karela, which was significantly different $(p<0.01)$ from the results obtained in the standard test $(19.6 \pm 2.2 \%)$ and in the test with added karela juice $(19 \cdot 2 \pm 2 \cdot 0 \%)$

\section{Discussion}

We have confirmed the hypoglycaemic effect of karela juice in animals ${ }^{3}$ and shown that it is not due to hyperinsulinaemia previous studies have shown that it does not result from reduced intestinal absorption. ${ }^{4}$ Our study has shown clearly for the first time that karela improves glucose tolerance in diabetes, confirming previous anecdotal reports. ${ }^{15}$ The effect was most pronounced with raw juice, but a small improvement occurred with fried karela.

As serum insulin concentrations were not increased karela may directly influence hepatic or peripheral glucose disposal. The reduction in glycosylated haemoglobin in patients receiving hypoglycaemic agents suggests an extrapancreatic effect. Karela has been used extensively in fringe medicine without serious side effects and merits further study. Doctors supervising Asian diabetics should be aware of its hypoglycaemic properties.

We thank Mr Nicholas Tully for help with the statistical analyses, Ames Pharmaceuticals for financial support, Mrs C Upton for typing the manuscript, and Mrs D Hammond for preparing the figure.

\section{References}

1 Pons JA, Stevenson DS. The effect of Momordica charantia in diabetes mellitus. Puerto Rico fournal of Public Health and Tropical Medicine 1943; 19:196-215.

2 Welch SG, Boucher BJ. A rapid microscale method for the measurement of haemoglobin A $(a+b+c)$. Diabetologia 1978;14:209-11.

${ }^{3}$ Pabrai PR, Sehra KB. Effect of Momordica charantia on blood sugar in rabbits. Indian fournal of Pharmacy 1962;24:209-13.

4 Gupta SS, Seth CB. Effect of momordica charantia linn (karela) on glucose tolerance in albino rats. $\mathcal{F}$ Indian Med Assoc 1962;39:581-4.

${ }^{5}$ Aslam M, Stockley IH. Interaction between curry ingredient (karela) and drug (chlorpropamide). Lancet 1979;i:607.

(Accepted 14 April 1981)

\title{
Labetalol-induced toxic myopathy
}

\author{
AVISHAI TEICHER, TALMA ROSENTHAL, ESTHER KISSIN, IDA SAROVA
}

\begin{abstract}
Labetalol has been successful in treating hypertension, and few side effects have been reported, although there have been cases of muscle pain during treatment. A patient with essential hypertension treated with labetalol $600 \mathrm{mg}$ daily complained of muscle pains, particularly in the legs. No neurological abnormality was found, but the activity of muscle enzymes in the blood was high. Findings on electromyography were compatible with myositis
\end{abstract}

\footnotetext{
Chaim Sheba Medical Centre, Tel-Aviv University Sackler Schoo of Medicine, Tel-Hashomer, Israel

AVISHAI TEICHER, MD, instructor, hypertension unit TALMA ROSENTHAL, MD, associate professor, hypertension unit ESTHER KISSIN, MD, staff member, hypertension unit IDA SAROVA, MD, senior lecturer, department of neurology
}

and electron microscopical findings suggested toxic myopathy. Labetalol was stopped for 10 days, and the muscle pain disappeared and enzyme activity returned to normal. When labetalol was restarted the pain returned and enzyme activities rose.

Myopathy should be considered in patients experiencing muscle pain after treatment with labetalol.

\section{Introduction}

Labetalol is a relatively new hypotensive agent, with competitive antagonist activity in both alpha- and beta-adrenergic receptors. ${ }^{1}$ Its effectiveness in the treatment of hypertension has not been impeded by serious side effects. Rare instances of muscle pain during treatment have been mentioned in the published reports, ${ }^{2-4}$ but there has been no report of labetalol-induced toxic myopathy. We describe a case in which labetalol treatment was complicated by toxic myopathy, which disappeared when the drug was withdrawn and withdrawal of the drug resulted in disappearance of the condition. 